\title{
MUDANÇAS NA ORGANIZAÇÃO CIENTIFICA DO TRABALHO E NA EDUCAÇÃO: QUAL A RELAÇÃ̃O?'
}

Work and Education Scientific Organization Changes: What the relation?

Giselia Antunes Pereira*

Nilza Maria Vilhena Nunes Costa**

Vanessa de Almeida Maciel***

\section{Resumo}

Este estudo tem o interesse em discutir contribuições de uma problemática centrada no binômio educação e trabalho. No âmbito de uma revisão da trajetória da organização científica do trabalho procurou-se destacar os principais processo técnicos de produção, a saber: fordismo, taylorismo, toyotismo e kalmarismo. Neste diálogo, sobressaem autores, que por sua vez, participam desse debate mesmo que de maneira específica. Procurouse, fundamentalmente, problematizar qual a relação entre as mudanças ocorridas na organização cientifica do trabalho e na Educação. Realiza-se uma fundamentação teórica, com o objetivo de trazer subsídios teóricos que apontam para as necessidades de se investigar e aprofundar questões acerca desta temática, onde se sinalizam mudanças importantes na organização dos processos de trabalho.

* Professora Colaboradora da Universidade Federal de Santa Catarina; mestrado e doutorado em Didática pela Universidade de Aveiro, Portugal. Email: giselia@yahoo.com

** Professora Catedrática da Universidade de Aveiro; mestrado e doutorado em Educação pela University of London, Inglaterra. Email: nilza@dte.ua.pt

**** Professor Substituto da Universidade Federal de Santa Catarina; mestrado em Educação pela Universidade Federal de Santa Catarina. Email: vanessa.almeidamaciel@gmail.com 
mudanças na organização...

Palavras-chave: Organização do trabalho, paradigmas de produção, educação e trabalho

\section{Abstract:}

A discussion on a binomial problematic between work and labor will be develop in this study. The main production process techniques are highlighted according a revision of the scientific work organization trajectory and are: fordism, taylorism, toyotism and kalmarism. In this dialog, authors who participate in a specific quarrel are remarked. The relation between the occurred changes in the education and work scientific organization are fundamentally collated. A theoretical revision were made to bring out theoretical subsidies that shows a necessity of a deeper investigation about questions on this subject in which important changes in the labor organization process were signalized.

Keywords: Work organization, production paradigms, education and work.

\section{MUDANÇAS NA ORGANIZAÇÃO DO TRABALHO}

A introdução de novas tecnologias desencadeou uma série de efeitos sociais. Esses efeitos, que se podem chamar de "impactos sociais", repercutiram nos processos de trabalho, na qualificação da força de trabalho, nas próprias condições de trabalho, na saúde dos trabalhadores e, conseqüentemente, nas políticas de ocupação, afetando diretamente a questão do emprego (Deluiz, 2004). O uso de novas tecnologias trouxe a diminuição do trabalho necessário, que se traduz na economia do tempo de trabalho, uma vez que, com a presença da automação (pela microeletrônica), começou a ocorrer a diminuição dos coletivos operários e uma mudança na organização dos processos de trabalho.

A análise acerca dos impactos sociais, acima referidos, na indústria aponta para uma série de modificações nos processos de trabalho, decorrentes da alteração no paradigma industrial fordista nos anos noventa do século XX e reflete as mudanças organizacionais derivadas da introdução das novas tecnologias. Embora podendo não ser a principal causa, os avanços 
da ciência e da tecnologia, resultantes do investimento do grande capital e dos estados, passam a ser estruturalmente constituintes do novo modo de acumulação contribuindo, desta forma, para o desemprego. Isto acontece não apenas porque os investimentos geram poucos postos de trabalho, mas, também, porque os geram no setor mais dinâmico que, não por acaso, vêm sistematicamente substituindo a força de trabalho pela tecnologia, como estratégia de competitividade e imperativo de sobrevivência das grandes empresas no âmbito da internacionalização (Kuenzer, 1999). Para Azevedo (2001), importantes análises têm sido desenvolvidas em torno da questão da adoção generalizada de novas tecnologias na produção de bens e de serviços. Para este autor a tese mais comum consiste em salientar que se assiste a uma crise do modelo fordista de produção, o qual está a dar lugar a um modelo considerado "pós-taylorista e pós-fordista" ou de "produção flexível”, Deste novo modelo pós-fordista, dentre outros pressupostos, está o de uma nova exigência em termos de qualificações profissionais.

De acordo com Lopes (1995), a evolução do processo tecnológico pôs em causa a filosofia de qualificação. As mudanças ocorridas no processo tecnológico, segundo a mesma autora, tiveram na sua gênese a crise energética do princípio dos anos 70 do século XX, constituída como provocadora principal das mudanças que voltariam a modificar a função da produção. Como efeito, desta crise houve um encarecimento imprevisto das matérias-primas, num quadro de estagnação do processo de produção, não permitindo manter a margem de competitividade que se desejava. Em conseqüência disso as empresas reagiram, pela contenção dos custos salariais, com ações mascaradas dos direitos trabalhistas. Anteriormente a esta crise energética, já havia, no entanto, rumores de contestação da organização do trabalho que subjazia ao modelo taylorista, assente em estruturas de controle autoritário no interior das empresas (Lopes, 1995).

O modelo predominante de organização do trabalho neste período dos anos 70 do século XX teve a sua origem nas transformações em torno da divisão do trabalho ocorridas na segunda metade do século XX. Neste modelo foi decisivo a contribuição de F. Taylor (1856-1915) e H. Ford (1863-1947). Tudo se iniciou com Taylor ao estudar os gestos dos 
funcionários, com um cronômetro na mão, de modo a promover simplificações e melhorias. O seu método, de organização científica do trabalho, estréia uma divisão parcelar do desempenho de cada trabalhador a partir de um sistema de controle dos tempos ociosos de trabalho (Azevedo, 2001). Na organização taylorista a inovação e a aprendizagem surgem como desvios da produção, nitidamente distantes da fase do funcionamento industrial (Correia, 1996), na qual:

os estágios profissionais e a formação em alternância constituem os modelos institucionais acionados pelos sistemas de formação para assegurarem a adaptação prévia dos recursos humanos a exigências sociais e técnicas das organizações do trabalho: a formação poderia ser mais ou menos funcionalmente adaptada a estas organizações mas nunca poderia inferir nelas (Correia, 1996, p. 96).

Depois do modelo de organização científica do trabalho se ter propagado pelos EUA e pela Europa, Henry Ford montava, em 1913, nas fábricas da Ford, de Detroit, a pioneira linha de montagem automobilística (Wood, 1992) - ver Fig. 1
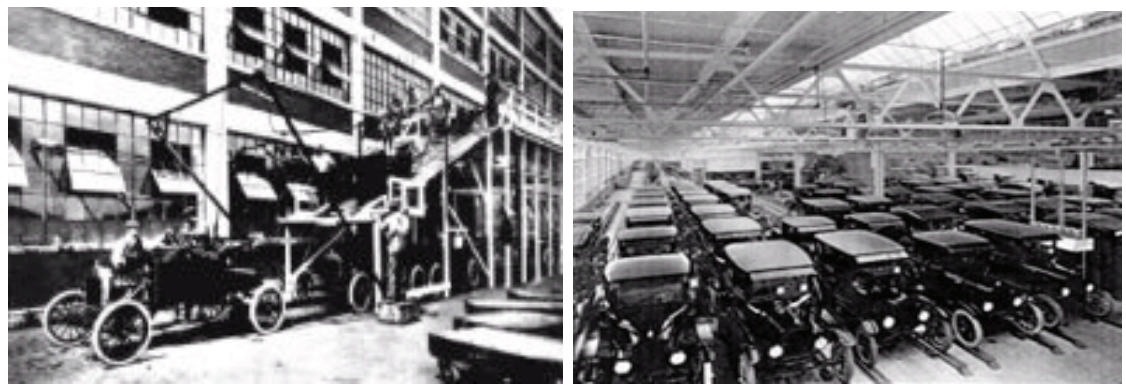

Figura 1: Imagens da Fábrica da Ford, Motor Company, em Highland, no Michigan onde foi introduzido a primeira linha de montagem em 1913, para o modelo $\mathrm{T}$ 
Com isso Ford desejava, tal como Taylor, para além de dar continuidade ao objetivo de conter os tempos mortos existentes nos postos de trabalho, reduzir rigorosamente os tempos mortos entre os postos de trabalho, numa concepção mais horizontal do processo de produção. Com efeito, conseguiu-se reduzir o tempo necessário para se montar um carro, face à articulação, mecânica e fragmentada, de muitos postos de trabalho (Azevedo, 2001).

Azevedo (2001) refere que a organização do trabalho, a produção e o consumo de massas estão intensamente relacionados no modelo fordista. $\mathrm{O}$ autor acrescenta, ainda, que desta era surgiu um novo surto econômico, em que as economias originadas pela produção em série viabilizavam redução nos preços dos produtos, aumento dos salários e da ocupação laboral de vastas camadas da população. Foram, ainda, realizadas importantes conquistas de cunho social, tais como garantias de emprego, salário-desemprego e aposentadoria. Houve, também, crescimento e fortalecimento dos sindicatos. Os contratos de trabalho começaram a ser assinados coletivamente.

Esse "método americano" de trabalho (também referido por paradigma sociotécnico, racionalização do processo técnico ou ainda modelo de Organização Científica do Trabalho) seguia linhas hierárquicas rígidas, com uma estrutura de comando partindo da alta direção e descendo até ao trabalhador da fábrica (Brígido, 2002). Os operários perderam, assim, o controle do processo produtivo como um todo e passaram a ser controlados rigidamente por técnicos e administradores - ver Fig.2.

Segundo Wood (1992), os mercados de massa ficavam garantidos devido ao aumento da capacidade de compra dos próprios trabalhadores. Embora ocorresse uma expansão dos mercados internacionais, eram os mercados internos que garantiam o consumo da maior parte da produção. Nascia a sociedade de consumo. Frigoríficos, máquinas de lavar roupa, telefone e até automóveis passaram a ser produtos de uso comum (Wood, 1992).

O sucesso do paradigma taylorista-fordista pode ser percebido à medida que essa verdadeira "técnica" de trabalho a favor do capital foi, gradativamente, ultrapassando os muros da fábrica, invadindo outros 

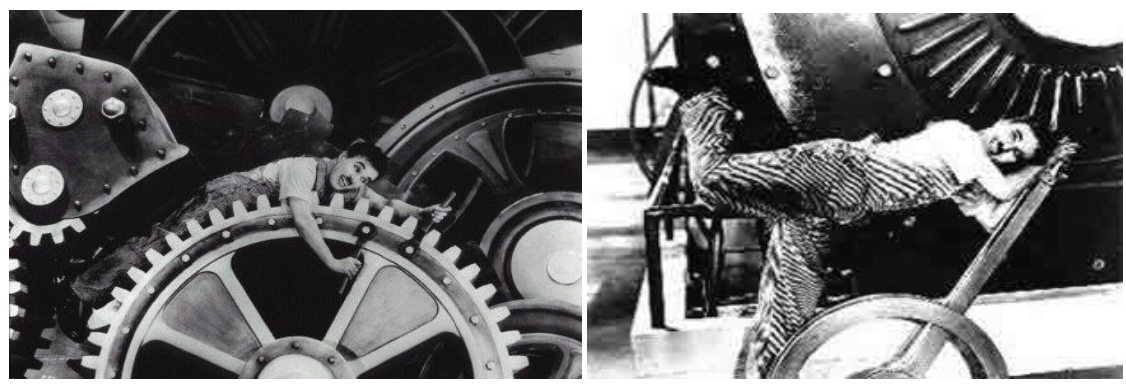

Figura 2: Cenas do filme “Tempos Modernos”, Estados Unidos, 1936, interpretado por Charles Chaplin, em que mostrava a vida de um operário na linha de montagem em uma fábrica com padrão fordista.

espaços de diferentes setores sociais. Para Bianchetti e Palangana (2000) um destes setores de influência foi, sem dúvida, a escola. Para os mesmos autores esse fato trouxe repercussões educacionais importantes, uma vez que a escola passa a preparar para o trabalho numa perspectiva segundo a qual a questão do cognitivo e do conhecimento permanece em segundo plano.

A prioridade é educar no trabalhador as atitudes, as disposições, as formas de comportamento, de conduta e de aceitação das relações sociais vigentes. Não por acaso, em termos formais, logo se passou a manifestar uma espécie de homogeneização, inclusive no nível do organograma e das denominações dos cargos-funções, tanto na organização das fábricas quanto na das escolas (ver Tabela 1).

No modelo fordista o trabalho subordinado é muito especializado e pouco qualificado e está, ainda, sujeito a um forte controle hierárquico (Azevedo; 2001). Segundo este autor, o cenário macroeconômico do pósguerra, conhecido por Trinta Gloriosos (1945 - 1975) ou Era de Ouro, e em que ocorreu um crescimento forte e constante com uma positiva tendência para aumento de consumo, propiciou a permanência deste modelo centralizador e hierárquico.

Contudo, após um ciclo virtuoso do sistema de produção fordiano, e do seu paradigma sociotécnico, o sistema taylorista/fordista de organização 
revista tecnologia e sociedade

\begin{tabular}{|l|l|}
\hline \multicolumn{1}{|c|}{ Fábrica } & \multicolumn{1}{c|}{ Escola } \\
\hline Diretor & Diretor \\
\hline Supervisor & Supervisor \\
\hline Assistente Social & Orientador Educacional \\
\hline Psicólogo & Psicólogo \\
\hline Operários & Professores \\
\hline Produtos & Alunos \\
\hline \multicolumn{2}{|c|}{ Saídas } \\
\hline \multicolumn{2}{|c|}{ Mercado } \\
\hline
\end{tabular}

Tabela 1: Equivalências das tipologias dos cargos e funções exercidos na fábrica e na escola.

da produção e do trabalho entra em crise, deixando de satisfazer, em particular, as necessidades econômicas (Azevedo, 2001; Martins, 1999).

O modelo taylorista/fordista apresentava um conjunto de limitações que passaram a ser bem evidenciadas nos anos 60 e 70. Segundo Azevedo (2001) as limitações essenciais deste modelo eram:

- a burocracia taylorista, que tornou excessivamente pesada as relações trabalhistas;

- a fragmentação fordista das funções e dos postos de trabalho, que dificultou novos ganhos de produtividade.

Mas é na passagem dos anos 90 do século $\mathrm{XX}$ que se veio acentuar a necessidade de alterar o perfil do processo técnico, decorrente de uma crise econômica global, a qual, por sua vez, veio atingir a competitividade das empresas e produzir as emergentes redefinições dos fatores produtivos. Ao nível das qualificações esta mudança veio fortalecer o papel da empresa na contribuição, no domínio da inovação, de modelos de formação e de qualificação perspectivando novas estratégias de gestão da mão-de-obra (Lopes, 1995).

Neste período a concorrência econômica acentua-se e, com isso, surgem novas formas de competir (Martins, 1999). O conceito de produção 
flexível, que é contraposto ao conceito de produção em série ou produção em massa, é freqüentemente referido no novo modelo de produção (Azevedo, 2001). De acordo com Carvalho (2003), as estratégias do novo plano de racionalização apontam para os seguintes dois aspectos:

- aspecto do mercado, mudança para produtos de alta qualidade e diversidade;

- aspecto da produção, utilizando as potencialidades das novas tecnologias, compatibilizando, de forma mais abrangente possível, a automação e a flexibilidade.

Desta forma, a saída foi investir num novo modelo que rompesse com aquilo que era considerado a rigidez do modelo fordista. Vários autores (Azevedo, 2001; Lopes, 1995; Martins, 1999) vêm o enfoque na flexibilização como sinal de ruptura que está a marcar a transição do padrão fordista ao padrão vigente. Os mesmos autores são consensuais no conjunto de afirmações, que a seguir se explicita, tradutoras das atuais mudanças que está a sofrer o processo técnico.

A ordem de flexibilizar, correspondendo à substituição da rigidez nos processos de produção, nas formas de ocupação da força de trabalho, nas garantias trabalhistas e nos mercados de massa. Com isso, os países de economia avançada precisaram criar, internamente, condições de competitividade. A saturação dos mercados acabou por gerar uma produção diversificada para atender a consumidores diferenciados. Como efeitos desta transição também foram alterados os contratos de trabalho que passaram a ser mais flexíveis. Diminuiu o número de trabalhadores permanentes e cresceu o número de trabalhadores temporários. Flexibilizaram-se os salários, cresceram as desigualdades salariais, segundo a qualificação dos empregados e as especificidades da empresa. Em muitas empresas, juntouse o que o taylorismo separou: o trabalhador pensa e executa. Os sindicatos viram reduzido o seu poder de representação e de reivindicação. Ampliouse o desemprego.

O novo modelo de produção flexível, designado por alguns de toyotismo, vem, assim, modificar as relações de trabalho, com ênfase à polivalência multifuncional dos trabalhadores, cujo trabalho é realizado 
por equipes, com recurso constante à subcontratação, gerando ao lado de pequenos grupos de emprego estável grande volumes de empregos instáveis (Azevedo, 2001). Estas mudanças implicaram, também, aberturas diferentes ao investimento na formação profissional. Segundo Lopes, este “(...) é visto então como o melhor meio de reforçar a capacidade negocial do trabalhador, o qual deverá especializar-se na gestão do seu port-folio de diplomas de formação" (p. 11, 1995).

Ao contrário do taylorismo e do fordismo, que buscam o aumento da produtividade a partir da otimização dos postos de trabalho individuais, o toyotismo olha para o processo produtivo buscando reduzir os seus entraves através da eliminação de acumulação na linha, ou seja, o material em causa deve ser somente o necessário para atender a determinada encomenda (Régnier, 1997b). Este princípio estende-se dos materiais e equipamentos ao pessoal, dando lugar à fábrica na qual predomina o mínimo necessário ou "fábrica magra" (Azevedo, 2001; Régnier, 1997). Uma vez que a "fábrica magra” é também um espaço de flexibilidade do trabalho, o sentido de polivalência, entendido como a capacidade de exercer várias funções diferentes, passa a ser requisitado de modo a que produtos, processos e trabalhadores funcionem na mesma coerência de flexibilização (Régnier, 1997).

Em Wood (1992), vê-se como um dos elementos de maior destaque do modelo toyotista é o chamado just-in-time (na hora certa). Wood (1992) oferece-nos a referência histórica deste modelo e indica-nos que este surgiu, pela primeira vez, na Toyota japonesa, em meados da década de 70 do século XX, pelo engenheiro Tahichi Ohno. Como refere o autor, este modelo japonês originou da necessidade de criar uma alternativa aos poucos espaços para armazenar matérias-primas, peças intermediárias ao processo produtivo ou, ainda, mercadorias já produzidas. Desta forma, Tahichi Ohno dedicou-se à problemática de como produzir em pequenas quantidades, sem prejuízo da obtenção de lucros. A transformação do modelo produtivo começou a apoiar-se nas tecnologias que já vinham surgindo nas décadas do pós-guerra (automação e robotização) e nos avanços das novas tecnologias da informação. O método de produção americano, rígido e burocrático, foi, assim, substituído pelo método 
japonês de produção magra, no qual se agrega maquinarias modernizadas com uma nova engenharia de gerência e de administração de produção, na qual se desqualifica a organização hierarquizada. Agora, equipes formadas por engenheiros de projetos, por programadores de computadores e por operários interagem face a face, partilhando idéias e tomando decisões conjuntas. Tendo por base o princípio "na hora certa", o novo método utiliza menos esforço humano, menos espaço físico, menos investimentos em ferramentas e menos tempo de engenharia para desenvolver um novo produto. A empresa possui um inventário informatizado, juntamente com melhores comunicações e transportes mais rápidos. O novo método de gestão da produção, impulsionado, em sua gênese sócio-histórica, pelo Sistema Toyota, tornou-se adequado à nova base técnica da produção capitalista, vinculada na Terceira Revolução Industrial. Esta exige novas condições de concorrência e de valorização do capital, como conseqüência da crise iniciada nos anos 1970.

De acordo com Brígido (2002), este novo modelo veio alterar substancialmente a organização do trabalho. De tal modo que o trabalhador passou a operar várias máquinas automáticas ao mesmo tempo. Apenas com pequenas alterações em programas de computador as máquinas passaram a executar tarefas diferentes para se ajustarem a novos produtos. Com efeito, passou a ser exigido dos operadores níveis mais elevados de formação, com uma preparação de atuação mais polivalente (Kovács, 1992)- ver Fig. 3.
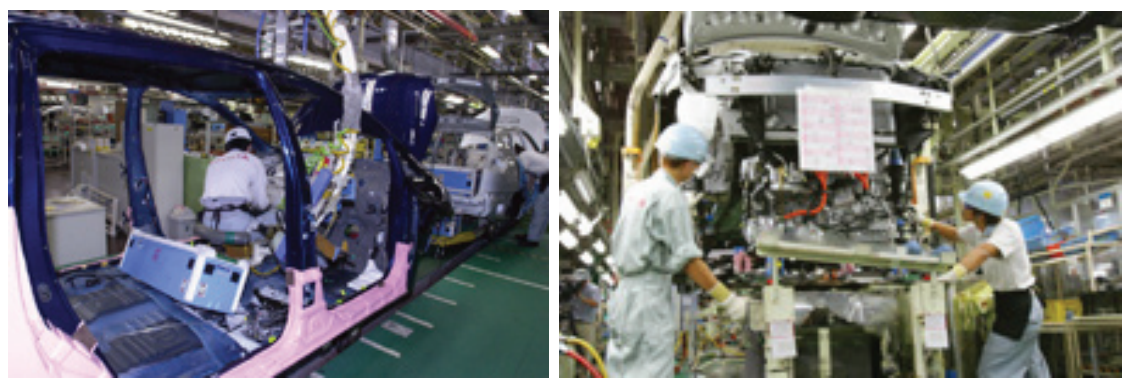

Figura 3: Imagens de uma moderna linha de produção da Toyota (extraídas da reportagem especial do Director Teruyuki Minoura sobre suas experiências com TPS - Sistema de Produção Toyota, Tokyo, 2003). 
Para Azevedo (2001), foi no final das últimas décadas do século XX que o toyotismo assumiu uma posição de objetivação universal tornando a flexibilidade num valor universal para o capital.

As grandes empresas começaram a distribuir para as pequenas e médias empresas subcontratadas certo número de atividades, tais como: concepção de produtos, pesquisa e desenvolvimento, produção de componentes, segurança, alimentação e limpeza. Segundo Wood (1992) esse fenômeno passou a ser conhecido como terceirização. Com isso, as grandes empresas reduziram as suas pesadas e dispendiosas rotinas burocráticas e as suas despesas com encargos sociais, concentrando-se naquilo que é estratégico para o seu funcionamento.

Nas empresas dos Estados Unidos, o modelo de produção toyotista não conseguiu reproduzir-se na sua totalidade (Brígido, 2002). Para Brígido (2002), isto aconteceu porque a indústria americana continuou ligada aos modelos taylorista/fordista e, além disso, apenas uma minoria dos empresários considerava necessário efetuar uma mudança. Assim, apenas as empresas que estavam mais expostas à concorrência internacional se preocuparam em ajustar-se ao modelo japonês, mesmo que de forma parcial (Brígido, 2002). Depois de ter explicitado o cenário da tamanha resistência no contexto americano, o mesmo autor vai mais longe e relata o processo de transição entre os modelos tradicionais e o toyotista, no referido contexto. Brígido (2002) começa por referir que, somente a partir dos anos 70 do século XX, o governo americano começou a preocupar-se com a questão do trabalho e da sua organização e passou a estudar os processos japoneses. Por conta disso, aponta o autor, criou-se a Comissão Nacional sobre a Excelência em Educação, tendo o trabalho desta Comissão resultado na publicação de um relatório "Uma nação em risco", no qual alertava a nação para os riscos que corria em não aderir ao novo modelo de produção. Tal relatório reforçou que a excelência americana alcançada no comércio, na indústria, na ciência e na inovação tecnológica estava a ser ultrapassada por seus concorrentes.

Já na década de 80 do século XX, e após inúmeras tentativas de alteração do seu sistema de produção, a General Motors realizou acordos com a empresa japonesa Toyota, onde passou a adotar o modelo japonês 
às condições americanas. A implementação do novo modelo implicou negociações com os sindicatos, nas quais se assegurava, por um lado as garantias de estabilidade no emprego por parte da empresa e, por outro, o compromisso dos trabalhadores em aceitar as novas regras e submeter-se à formação. Assim, cada trabalhador teria que fazer um curso para tomar conhecimento de todos os detalhes do processo de produção, tendo sido cada posto de trabalho cuidadosamente submetido a análise ocupacional. $\mathrm{Na}$ altura, foram encomendados estudos que revelaram que os novos sistemas adotados chegavam a ser duas vezes mais produtivos que os tradicionais, da gestão científica taylorista (Womack, op. cit. Brígido, 2002).

É a este período de mudanças na estrutura produtiva que Azevedo (2001) se refere como fase de transição pós-fordista. Os aspectos mais decisivos desta fase passam: pelo aumento da flexibilidade na escala global, pela mobilidade de capital e pela liberdade para colonizar e mercantilizar praticamente todas as esferas, eliminando-se as fronteiras sociais e geográficas, gerando-se um processo de descentralização. Porém, conforme refere Azevedo (2001) sobre a transição do fordismo para o pós-fordismo, deve-se ter em consideração que as características do fordismo não foram totalmente extintas. Até mesmo Ohno, figura ligada ao novo método de produção, reconhece que é mais importante insistir sobre as continuidades do que sobre as rupturas do toyotismo em relação ao taylorismo/fordismo (Wood, 1992). De certo modo, consoante ao mesmo autor, o toyotismo conseguiu ultrapassar alguns aspectos predominantes da gestão de produção da grande indústria do século XX, inspiradas no taylorismo e no fordismo e que instauraram a parcelização e a repetitividadade do trabalho. Mas, na base da intensificação do ritmo do trabalho que existe no toyotismo, persiste uma nova repetitividade do trabalho.

Em alternativa aos modelos referidos existe, ainda, o modelo holístico. Este modelo, desenvolvido na Suécia, foi idealizado por Gyllenhammar, gerente da fábrica Volvo, em Kalmar (ver Fig. 4).

Em Brígido (2002) verifica-se que este novo paradigma de produção chamado também de Kalmarismo, partiu de conceitos totalmente inovadores: organização baseada em grupo, delegações de funções e responsabilidade coletiva. Segundo Brígido (2002), a primeira fábrica no mundo construída 

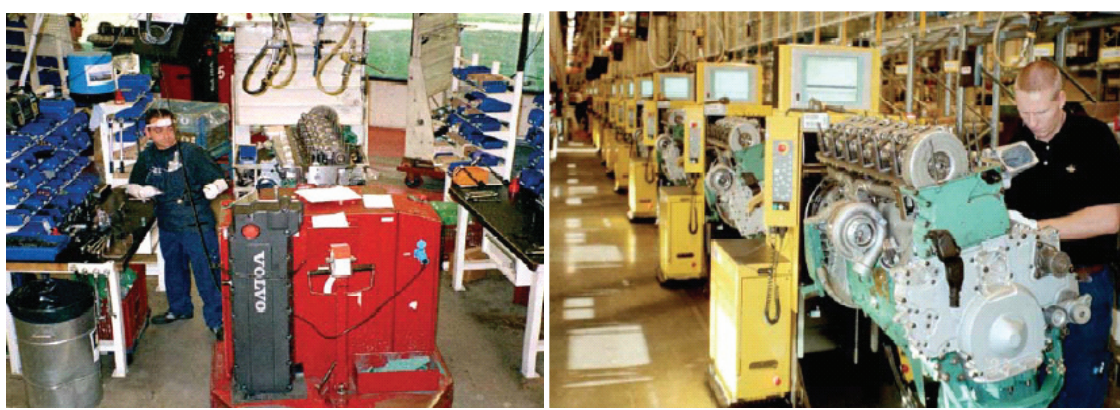

Figura 4: Imagens do sistema de produção paralela substituído pelo sistema de produção em série - Fábrica da Volvo Kalmar, 2002.

sem linhas de montagem foi a da Volvo. Esta experiência relativa à Fábrica de Kalmar da Volvo constituiu o primeiro exemplo na Europa da adaptação da técnica às necessidades humanas e sociais inseridas num novo modelo de organização do trabalho em equipes semi-autónomas (Kovács, 1992).

Brígido (2002) caracteriza as condições desta fábrica ressaltando que a mesma era construída com muitas paredes e corredores, para separar cada equipe em seu próprio ambiente, e que as suas salas eram claras e bem arejadas com um nível de ruído reduzido. Contudo, acrescenta o autor, a maior inovação do modelo estava no sistema de transporte, mais flexível, por meio de uma esteira mecânica feita por veículos elétricos guiados automaticamente, onde os veículos não eram controlados pelas equipes, mas por uma central de computação. Dentro da descrição que o autor faz refere, ainda, que a fábrica de Kalmar levou em conta, diferentemente das fábricas tradicionais, os aspectos ergonômicos, sendo que um meio ambiente harmonioso levaria à motivação da equipe, capaz de cooperação no aumento da eficiência. O objetivo era criar uma fábrica que gerasse oportunidade aos empregados de comunicarem livremente, trabalharem em grupos, mudarem de um posto a outro e de se responsabilizarem pela qualidade do produto. Sobre este último objetivo Gyllenhammar declarou "quando um produto é feito por pessoas que encontram significado em seu trabalho, esse deve ser, inevitavelmente, um produto de alta qualidade" ( $\mathrm{p}$. 112, 1977). 
Como efeito, a este novo modelo centrado no fato humano e na organização, a qualidade tornou-se melhor, os custos mais competitivos e com possibilidade de mudanças flexíveis no produto (Kovács, 1992). Essas foram as razões que tornaram este modelo influente e divulgado.

No entanto, mesmo com a capacidade de produzir resultados tão positivos os novos modelos, reconhecidos como flexíveis, não são adotados em todas as empresas. Segundo Brígido (2002), isto pode estar associado ao fato de os sistemas de organização do trabalho serem variáveis e, ao mesmo tempo, dependerem da escolha do empregador. Para o autor uma única tecnologia pode ser aplicada de formas variadas, implicando diversos graus de qualificação dos trabalhadores. Além disso, o planejamento do trabalho também difere entre os diversos estilos de administração.

Alguns autores defendem que o modelo que predomina atualmente e que faz sucesso com a mão-de-obra barata do Terceiro Mundo é o modelo misto:

vestígios importantes de velhas estruturas e práticas da produção em série, e mesmo casos em que economias nacionais inteiras em particular a Coréia do Sul se lançaram, não apenas na via do desenvolvimento, mas conseguiram ainda se manter e progredir ao longo dos anos 80 graças a uma estratégia de produção em série. $E$ as experiências mais bem sucedidas do mundo industrial neste domínio parecem ter permitido a elaboração de uma estratégia mista no interior mesmo da produção, aliando equipamentos rígidos, especializados e ilhas de flexibilidade. Pode-se deduzir destas constatações que o sistema que emerge atualmente como suporte da recuperação econômica é um sistema misto, aliando as duas tecnologias (Piore e Sabel, p.13, 1984).

Em síntese, verifica-se que após os seus dias de glória, a crise na queda da produtividade enfrentada por diversos países colocaram em xeque o modelo de produção de massa (conjecturado pelos modelos tayloristas/ fordistas de produção). Face aos crescentes desenvolvimentos científicotecnológicos, particularmente às tecnologias de base microeletrônica e de 
comunicações e à emergência de modelos produtivos japoneses que se pautavam pela "produção magra" (de que o toyotismo é o melhor exemplo), praticamente todos os setores econômicos se viram diante da necessidade de reformular os seus métodos de produção. A palavra de ordem passou a ser "flexibilização": flexibilização de produtos (produção segundo a finalidade dos clientes), de processos (mudanças rápidas na linha de produção para se adequar aos novos produtos), de pessoas (trabalhadores competentes, multifuncionais e/ou polivalentes).

\section{CONSIDERAÇÕES FINAIS}

Atualmente, o trabalho constitui-se como um horizonte para qualquer pessoa, como uma referência obrigatória, mesmo que não se tenha acesso a ele (Duarte, 2005). Estudos mostram que ao nos remeter para o questionamento da função da escola as respostas que se obtêm, tanto por parte de alunos e pais, quanto de professores e demais educadores escolares, sempre convergem para a questão do trabalho.

Neste contexto, a educação deveria ter uma ligação natural com 0 mundo do trabalho, não apenas porque temos de trabalhar "no mercado de trabalho" e atender a novos paradigmas de produção, mas porque 0 trabalho constitui "o homem e a mulher".

O problema educacional está relacionado a sua crescente desvinculação ao mundo do trabalho, e não a subordinação da escola aos interesses da empresa. Olhando a questão sob a perspectiva da subordinação, realmente é pertinente interrogarmo-nos até que ponto a educação deve ser planejada em função dos interesses do mundo do trabalho e, em particular, do mundo empresarial. Porém, não parece sustentável que a educação ignore e se desvie completamente das relações com o trabalho, da sua complexidade, do seu conteúdo e da sua relevância. De qualquer forma é importante indicar que desde o surgimento das sociedades industriais a função principal que a sociedade delega e encarrega a escola é a de preparação para a incorporação ao mundo do trabalho. Há discrepâncias que se ressaltam quando se busca responder a questão clássica de educar para vida ou para o trabalho. Estas discrepâncias surgem, pois se trata de definir o significado de prepará-los para o mundo do trabalho, como se viabiliza o processo, as conseqüências 
de promoção de igualdade de oportunidades. Contudo, o desafio se encontra no ponto de equilíbrio entre atender a um novo paradigma de produção e compreender por outro lado a formação plena do cidadão.

\section{NOTAS}

1 Este trabalho originou-se de uma tese de doutorado e teve o seu aprimoramento por meio da discussão entre os autores. A tese intiula-se "Formação pós-secundária não superior: Os cursos de especialização tecnológica do programa Aveiro-Norte da Universidade de Aveiro - um estudo de avaliação da concepção ao impacte" . Este estudo foi financiado pela Fundação para Ciência e Tecnologia (processo $\left.n^{0} 13186 / 2003\right)$.

\section{REFERÊNCIAS}

AZEVEDO, J. (2001). Avenidas de liberdade - reflexões sobre política educativa. Porto: Edições ASA.

BIANCHETTI, L. e, PALANGANA, I. C. (2000). Sobre a Relação Histórica entre Escola e Sistema Produtivo: Desafios Qualificacionais. Boletim Técnico do Senac. v. 26, $\mathrm{n}^{0} .2$, Maio/Agosto. In: www.senac.br/informativo/bts/index.html - última consulta em Março de 2006.

BRÍGIDO, R. V. (2002). Certificación y normalización de competencias: Orígenes, conceptos y prácticas. Boletim Cintefor. $n^{0} .152$. p 51 - 74 .

CARVALHO, O. F. (2003). Educação e formação profissional - trabalho e tempo livre. Brasília: Plano Editora.

CORREIA. J. A. (1996). Sociologia da educação tecnológica. Lisboa: Universidade Aberta.

DELUIZ, N. (2004). A globalização econômica e os desafios à formação profissional. Boletim Técnico do Senac. v.30, $n^{0} .3$, Setembro/Dezembro. in: www.senac.br/ informativo/bts/index.html - última consulta em Março de 2006.

DUARTE. B. (2005). Educação e trabalho - Programa "escola de fábricas" in: http:// www.ricesu.com.br/ciqead2005/trabalhos/16.pdf - última consulta em Novembro de 2005. 
GYLLENHAMMAR, P. G. (1977). How Volvo adapts work to people. Harvard: Business Review. July-August. p.102 -113.

KOVÁCS, I., et al. (1992). Sistemas flexíveis de produção e reorganização do trabalho. Lisboa: Programa Específico de Desenvolvimento da Indústria Portuguesa.

KUENZER, A. Z. (1999). Educação profissional: categorias para uma nova pedagogia do trabalho. Boletim Técnico do Senac. v.25, $\mathrm{n}^{0} .2$, Maio/Agosto. In: www.senac. br/informativo/bts/index.html - última consulta em Março de 2006.

LOPES. M. C. (1995). Estratégias de qualificação e metodologias de avaliação entre a empresa, o mercado de trabalho e a convergência européia. Oeiras: Celta Editora.

MARTINS, A. M. (1999). Formação e emprego numa sociedade em mutação. Aveiro: Universidade de Aveiro.

PIORE, M. \& SABEL, C. (1984). The second industrial divide: possibilities for prosperity. New York: Basic books.

RÉGNIER, K. D. (1997). Alguns elementos sobre a racionalidade dos modelos taylorista, fordista e toyotista. Boletim Técnico do Senac. v. 23, $\mathrm{n}^{\circ}$. 2, Maio/Agosto. in: www. senac.br/informativo/bts/index.html - última consulta em Março de 2006.

WOOD, J. T. (1992). Fordismo, toyotismo e volvismo. Os caminhos da indústria em busca do tempo perdido. Revista de Administração de Empresas. São Paulo, no 32 Setembro/Outubro. p. 97 - 109. 